\title{
Physical Training in Chronic Obstructive Lung Disease
}

\author{
DAVID CHRISTIE,* M.B., M.R.A.C.P.
}

Brit. med. F., 1968, 2, 150-151

Physical training programmes to aid disabled patients are a comparatively recent development. Sloman et al. (1965) and Varnauskas et al. (1966) showed that in patients with cardiac disease physical training improved performance. Pierce et al. (1964) demonstrated its application to patients with chronic pulmonary disorders.

This paper shows that a graduated programme of physical training applied to outpatients with severe chronic airways obstruction results in improvement in well-being and exercise tolerance. This symptomatic improvement correlates with measurable change in cardiorespiratory function.

\section{Patients and Methods}

Eleven male patients were admitted to the training programme ; their physical characteristics are summarized in Table I. All had marked limitation of exercise capacity, nine being unable to walk at their own pace for 15 minutes or half a mile $(800 \mathrm{~m}$.) without a rest. Of the remaining two patients one (Case 9) was unable to keep up with others of the same age and sex on the flat, and the other (Case 10) was unable to keep up on hills and stairs. Severe virtually irreversible airways obstruction was present in all, with forced expiratory volumes in the first second (F.E.V..$_{1}$ ) consistently of 1 litre or less. All patients were observed for at least a month before entering the programme to ensure stability of clinical, radiological, and spirometric findings. None had evidence of cardiac failure or of ischaemic heart disease, either clinically or electrocardiographically. Throughout the training period-about two months -regular drug therapy with orciprenaline and choline theophyllinate was unchanged. An occasional short course of antibiotic was given to cope with intercurrent infection, and prednisone dosage was temporarily increased in Case 4 in the middle of the programme. Three patients (Cases 2,3, and 4) were on long-term low-dosage prednisone.

The training programme consisted of a 15-minute exercise period each morning, together with a daily walk of half to one mile ( 800 to $1,600 \mathrm{~m}$.). The exercise period was made up of four physical exercises of a repetitive nature as illustrated by Sloman et al. (1965), the severity and frequency of performance being adjusted to the patient's physical condition. This was followed by a five-minute stepping exercise in which the patient stepped up and down a convenient box or step 10-20 cm. high at a self-adjusted rate. However, the emphasis throughout the programme was less on specific exercises than on an attempt to impress each patient with the desirability of integrating physical activity into his daily life by, for example, walking instead of driving, clirsbing stairs instead of taking the lift.

Patients were studied before and after the training programme by means of a stepping-exercise test modified from Hugh-Jones and Lambert (1952), in which work done is measured from a knowledge of height of step, weight of patient, and rate of stepping (lift work). Each study consisted of five or six stepping exercises of increasing work-load performed consecutively, with a 20 -minute rest period between each.

The standard time of exercise was four minutes, the expired gas being collected over the last minute. The first exercise, or "zero lift work," consisted of the patient stepping backwards

* Senior Medical Officer, Randwick Chest Hospital ; Honorary Research Associate, Division of Thoracic Medicine, Department of Medicine, University of N.S.W., Sydney. and forwards horizontally at a rate of two steps a minute. The final exercise was the highest work-load the patient could maintain for at least three minutes, with gas collection again over the final minute.

At each work-load during the last minute of exercise the volume of expired gas was measured and analysed for oxygen and carbon dioxide content. The oxygen uptake, calculated from these data and expressed as $\mathrm{ml} . / \mathrm{min}$./sq. m. (body surface area), was related to work-load expressed as metre kilogram/ minute (mkg./min.). At submaximal work-loads this relation was linear, but at the highest levels of work the oxygen uptake was much less than that predicted from the linear relation determined at submaximal work. This oxygen uptake was regarded as the subject's "maximum oxygen uptake" (for purposes of this study). In 12 of the 21 studies carried out duplicate measurements of the maximum oxygen uptake were made ; the greatest difference found between replicate measurements was $7.6 \%$.

Patients breathed through a low-resistance valve-box, and gas collections were made into a 100-litre Douglas bag. Volumes were measured with a Parkinson-Cowan CD4 dry gas meter. Oxygen analyses were performed with a Beckman model E2 analyser, and for carbon dioxide a Godart pulmonanalyser model 44A was used. Vital capacity and forced expiratory volume were measured with a Collins 13.4-litre spirometer and expressed as litres B.T.P.S. The indirect maximum breathing capacity (M.B.C.) was calculated as F.E.V., multiplied by 40 . Haemoglobin and body weight were measured before and after training ; no consistent change in either was noted.

"Maximum work" can be defined in the present context as work in which at least part of the energy needed must come from anaerobic metabolism-that is, oxygen requirement is greater than maximum oxygen intake. Submaximal work can be defined as work in which oxygen requirements are less than the maximal oxygen uptake and energy demands can be met aerobically.

In this study the patients were their own controls, and in comparing effects at "maximal work" absolute figures are all that are required. However, to compare effects at differing submaximal work-loads some calculations are necessary. The highest work-load which was clearly submaximal was used as the basis of comparison. The expired minute-volume and the oxygen uptake were adjusted to a work-load of $100 \mathrm{Mkg} . / \mathrm{min}$. (SV100, $\mathrm{SVO}_{2} 100$ respectively) after Gandevia (1962). The arbitrary figure of $100 \mathrm{Mkg} . / \mathrm{min}$. was selected because the least extrapolation from the data was required at this work level.

Of the 11 patients one (Case 11) died three weeks after beginning the training programme. This 60 -year-old man was severely disabled with chronic irreversible airways obstruction and emphysema. His history was of chronic bronchitis of many years' standing, with about 10 years' progressive loss of exercise tolerance. He gave no history suggestive of ischaemic heart disease. On physical examination the blood pressure was 130/ 80 and there was no evidence of cardiac failure. An electrocardiogram was within normal limits, and a chest radiograph showed overdistended lungs with attenuation of mid-zonal and peripheral vascular markings. Six days before death the findings on physical examination were unaltered, the blood pressure being stable. Death occurred over a matter of hours, and at necropsy an extensive myocardial infarction was found with 
recent antemortem thrombus occluding the right coronary artery. In spite of the temporal association it is unlikely that the physical training programme caused or accelerated his death, though the possibility of such an occurrence received careful consideration even before the study began.

Varnauskas et al. (1966) and Sloman et al. (1965) have shown the beneficial effects of physical training in patients with ischaemic heart disease, and it is difficult to conceive that the haemodynamic effects of physical training described by Andrew et al. (1966) and also by Varnauskas et al., could contribute to a myocardial infarction. Any continued form of therapy in patients of this age group, who are specially selected because of the presence of serious disease, is likely to be associated with some mortality. No ill effects were noted in other patients.

\section{Results}

Of the 10 patients studied before and after a programme of physical training nine stated that their exercise tolerance had considerably improved, though ventilatory function tests showed random change of a minor nature only (Table I). The nature of this improvement was investigated with respect to two functions-namely, performance at their maximum work level and their performance at work, which was submaximal.

Maximum work-load tolerated increased after training, and this was associated with an increase in minute-volume and in maximum oxygen uptake (Table II). As motivational factors are impossible to assess in a study of this kind, no conclusions may be drawn from the absolute increase in maximal work. However, it was also noted that the minute-volume at maximum work, expressed as a percentage of the indirect maximum breathing capacity, showed a marked increase; in all but one

\begin{tabular}{|c|c|c|c|c|c|c|c|c|c|c|}
\hline \multicolumn{2}{|c|}{ TABLE } & \multicolumn{2}{|l|}{$T-P$} & \multicolumn{2}{|c|}{ Characteristics } & \multicolumn{2}{|c|}{5 Before and } & \multicolumn{2}{|c|}{ After } & ring \\
\hline \multirow{2}{*}{$\begin{array}{l}\text { Case } \\
\text { No. }\end{array}$} & \multirow{2}{*}{ Age } & \multicolumn{2}{|c|}{$\begin{array}{c}\text { Weight } \\
(\mathrm{kg.})\end{array}$} & \multicolumn{2}{|c|}{$\begin{array}{l}\text { B.S.A. } \\
\text { (sq.m.) }\end{array}$} & \multicolumn{2}{|c|}{$\begin{array}{c}\text { F.E.V.1 } \\
\text { (1. B.T.P.S.) }\end{array}$} & \multicolumn{2}{|c|}{ (1. B.T.P.P.S.) } & \multirow{2}{*}{$\begin{array}{l}\text { Train- } \\
\text { ing } \\
\text { Period } \\
\text { (weeks) }\end{array}$} \\
\hline & & B & A & B & A & B & A & B & A & \\
\hline $\begin{array}{r}1 \\
2 \\
3 \\
4 \\
5 \\
6 \\
7 \\
8 \\
9 \\
10 \\
11\end{array}$ & $\begin{array}{l}67 \\
63 \\
57 \\
61 \\
57 \\
63 \\
57 \\
70 \\
57 \\
46 \\
60\end{array}$ & $\begin{array}{l}69 \cdot 0 \\
54 \cdot 0 \\
51.6 \\
66.5 \\
52.5 \\
67.5 \\
51.9 \\
56 \cdot 6 \\
63 \cdot 0 \\
61.5 \\
70 \cdot 4\end{array}$ & $\begin{array}{l}71.6 \\
54.0 \\
52.1 \\
70.4 \\
51.9 \\
65.4 \\
51.7 \\
58.0 \\
58.0 \\
63.9\end{array}$ & $\begin{array}{l}1.76 \\
1.58 \\
1.57 \\
1.75 \\
1.59 \\
1.75 \\
1.63 \\
1.59 \\
1.75 \\
1.74 \\
1.81\end{array}$ & $\begin{array}{l}1.79 \\
1.58 \\
1.58 \\
1.80 \\
1.58 \\
1.73 \\
1.63 \\
1.61 \\
1.68 \\
\end{array}$ & $\begin{array}{l}0.65 \\
0.65 \\
0.84 \\
0.73 \\
0.45 \\
0.66 \\
0.77 \\
0.66 \\
0.77 \\
1.01 \\
0.65\end{array}$ & $\begin{array}{l}0.59 \\
0.77 \\
0.67 \\
0.77 \\
0.47 \\
0.65 \\
0.75 \\
0.38 \\
0.63 \\
0.85\end{array}$ & $\begin{array}{l}2.29 \\
2.10 \\
2.80 \\
2.59 \\
1.62 \\
1.90 \\
2.76 \\
1.65 \\
2.48 \\
2.98 \\
1.74\end{array}$ & \begin{tabular}{|l|}
2.08 \\
2.98 \\
2.88 \\
3.27 \\
2.30 \\
2.44 \\
1.68 \\
1.80 \\
2.28 \\
3.19 \\
\end{tabular} & $\begin{array}{r}9.6 \\
9.0 \\
17.0 \\
7.5 \\
8.7 \\
7.9 \\
6.0 \\
11.1 \\
12.9 \\
7.3\end{array}$ \\
\hline$\overline{\text { Mean }}$ & $59 \cdot 8$ & \multicolumn{2}{|c|}{$60 \cdot 1$} & \multicolumn{2}{|c|}{1.68} & \multicolumn{2}{|c|}{0.68} & \multicolumn{2}{|c|}{$2 \cdot 37$} & 9.7 \\
\hline
\end{tabular}

\begin{tabular}{|c|c|c|c|c|c|c|}
\hline $\begin{array}{l}\text { Case } \\
\text { No. }\end{array}$ & $\begin{array}{c}\text { Maximal } \\
\text { Oxygen } \\
\text { Uptake } \\
\text { (ml./sq.m.) }\end{array}$ & $\begin{array}{c}\text { Minute } \\
\text { Volume at } \\
\text { Maximum } \\
\text { Work } \\
\text { (1./min.) }\end{array}$ & $\begin{array}{c}\text { Maximum } \\
\text { Work } \\
\text { (Mkg./ } \\
\text { min.) }\end{array}$ & $\begin{array}{c}\text { Minute } \\
\text { Volume at } \\
\text { Maximum } \\
\text { Work as \% } \\
\text { of M.B.C. }\end{array}$ & $\begin{array}{c}\text { SV100 } \\
\text { (1./min.) }\end{array}$ & $\begin{array}{l}\mathrm{SVO}_{2100} \\
\text { (ml./min.) }\end{array}$ \\
\hline $\begin{array}{c}8 \\
6 \\
9 \\
3 \\
7 \\
10 \\
2 \\
5 \\
1 \\
4\end{array}$ & $\begin{array}{c}364 \\
(+24) \\
431 \\
(+147) \\
480 \\
(+95) \\
427 \\
(+193) \\
484 \\
(+123) \\
613 \\
(-44) \\
598 \\
(+77) \\
423 \\
(+132) \\
474) \\
(+110) \\
476) \\
(+172)\end{array}$ & $\begin{array}{c}13.30 \\
(+0.12) \\
21.42 \\
(+2.18) \\
21 \cdot 10 \\
(+5.80) \\
18.8 \\
(+6.08) \\
23.72 \\
(+4.78) \\
24.20 \\
(-1.50) \\
24.40 \\
(+1.60) \\
15.30 \\
(+2.80) \\
19.45 \\
(+3.23) \\
19.80 \\
(+9.50)\end{array}$ & $\begin{array}{c}123 \cdot 0 \\
(-5) \\
78 \cdot 4 \\
(+120) \\
189 \\
(+111) \\
103 \\
(+122) \\
113 \\
(+82) \\
258 \\
(-17) \\
292 \\
(+1) \\
152 \\
(-1) \\
190 \\
(+96) \\
145 \\
(+150)\end{array}$ & $\begin{array}{c}50 \cdot 4 \\
(+38 \cdot 1) \\
80 \cdot 0 \\
(+11 \cdot 0) \\
74 \cdot 5 \\
(+32 \cdot 5) \\
56 \cdot 0 \\
(+37 \cdot 0) \\
77 \cdot 0 \\
(+18 \cdot 0) \\
60 \cdot 0 \\
(+7 \cdot 0) \\
94 \cdot 0 \\
(-9 \cdot 5) \\
84 \cdot 5 \\
(+12 \cdot 5) \\
75 \cdot 0 \\
(+21 \cdot 0) \\
68 \\
(+27)\end{array}$ & $\begin{array}{c}17.05 \\
(-1.87) \\
32.77 \\
(-10 \cdot 79) \\
21.16 \\
(-0.68) \\
23.04 \\
(-3.67) \\
28.89 \\
(-4.47) \\
20.00 \\
(-2.02) \\
(-20.44 \\
(-1.09) \\
18.45 \\
(+1.60) \\
20.04 \\
(-2.02) \\
(-28.75 \\
(-10.50)\end{array}$ & $\begin{array}{c}703 \\
(+25) \\
1,040 \\
(-275) \\
808 \\
(-45) \\
860 \\
(-112) \\
907 \\
(-172) \\
811) \\
(-117 \\
678 \\
(+47 \\
850 \\
(+9) \\
867 \\
(-15) \\
1,187 \\
(-504)\end{array}$ \\
\hline $\begin{array}{l}\text { Mean } \\
\text { Signi- } \\
\text { ficance }\end{array}$ & $\begin{array}{c}+102.9 \\
P<0.002\end{array}$ & $\begin{array}{l}+3.46 \\
P<0.01\end{array}$ & $\begin{array}{l}+65.9 \\
P<0.01\end{array}$ & $\begin{array}{l}+19.5 \\
P<0.01\end{array}$ & $\begin{array}{c}-3.55 \\
P<0.05\end{array}$ & $\begin{array}{l}-115.9 \\
P<0.10\end{array}$ \\
\hline
\end{tabular}

Note: Initial figures refer to pretraining values. Figures in parenthesis refer to change with training. patient it exceeded $90 \%$, compared with a mean of approximately $70 \%$ before training.

At submaximal work-loads with minute-volumes and oxygen uptakes standardized to $100 \mathrm{Mkg}$. $/ \mathrm{min}$. there was a significant fall in minute-volumes but not in oxygen uptake (Table II). Reduction in minute-volume without a comparable fall in oxygen uptake implies an increase in "oxygen extraction" from inspired air.

\section{Discussion}

The present findings indicate that after a period of physical training outpatients with severe irreversible obstructive airways disease achieved higher work levels and higher maximum oxygen uptakes than before training, and in particular they were prepared to tolerate higher exercise minute-volumes in relation to their maximum breathing capacity. While the change may be related to motivation and psychological "tolerance" to the sensation of dyspnoea, the lower minute-volumes per unit of work during submaximal work suggest a physiological improvement. Reduction in minute-volume per unit of work after training is an expected finding (Pierce et al., 1964 ; Andrew et al., 1966), and might be due to a change in ventilatory equivalent or in oxygen cost of work. A decrease in ventilatory equivalent for oxygen, or increased "oxygen extraction," is present in this series as well as in the series of Andrew et al. and of Pierce et al., and it is interesting to speculate on the possibility of redistribution of pulmonary blood flow occurring as a training effect, with consequent better matching of gas and blood in the lung. Change in "efficiency" or in oxygen cost of work with training, in part a "skill effect," was not present to a significant degree in this group of patients. This finding is in accord with most work on the subject (Astrand, 1956; Varnauskas et al., 1966 ; Andrew et al., 1966), though Pierce et al. noted a decrease in the oxygen cost of work in his subjects.

The chief purpose of this study was not to confirm physiological changes already described, but rather to show that improvement in the lot of patients with severe chronic airways obstruction can be achieved on an outpatient basis, with little more supervision on patients than is usual in any clinical practice. Admission to hospital, while ideal for some purposes, is not feasible in the routine management of patients, many of whom have to earn a living.

\section{Summary}

Eleven patients with severe largely irreversible obstructive airways disease and marked loss of exercise tolerance were submitted to a physical training programme. One patient died during the programme, and reasons are advanced for suggesting that the cause was unrelated. Nine of the 10 subjects who completed the course experienced considerable improvement in well-being and exercise tolerance, and demonstrable increase in physical working capacity. These changes were associated with increase in maximal oxygen uptake, reduction in minuteventilation at submaximal work levels, and increase in maximum tolerated ventilatory volumes.

I am grateful to Associate Professor Bryan Gandevia for his interest in the project and help in preparing this paper. I am indebted to the Director, Division of Establishments, Department of Public Health, for permission to publish.

\section{REFERENCES}

Andrew, G. M., Guzman, C. A., and Becklake, M. R. (1966). F. appl. Physiol., 21, 603.

Asstrand, P. O. (1956). Physiol. Rev., 36, 307.

Gandevia, B. (1962). Amer. Rev. resp. Dis., 85, 378.

Hugh-Jones, P., and Lambert, A. V. (1952). Brit. med. f., 1, 65.

Pierce, A. K., Taylor, H. F., Archer, R. K., and Miller, W. F. (1964). Arch. intern. Med., 113, 28.

Sloman, G., Pitt, A., Hirsch, E. Z., and Donaldson, A. (1965). Med. F. Aust., 1, 4. Varnauskas, E., Bergman, H., Houk, P., and Björntorp, P. (1966). Lancet,
2, 8. 